\title{
VICO CIEGO EN SU CENTENARIO
}

\section{Bruno Pinchard \\ (Universidad Jean Moulin, Lyon 3)} RESUMEN: Ni emancipador ni restaurador, el pensamiento de Vico nos juzga desde la atalaya de su conciencia de
contradicciones definitivas de las evoluciones sociales. Esta es la razón por la que, desde 1992, he querido hablar,
a propósito de la Fabbrica della mente de nuestro autor, de una «Razón desdoblada», y no tengo argumentos, casi
treinta años después, para renunciar a esta primera formulación.
PALABRAS CLAVE : G. Vico, $350^{\circ}$ Aniversario, «razón desdoblada», nihilismo, decadencia, romanidad, B. Pinchard.

\section{Blind Vico in his centenary}

ABSTRACT: Neither emancipator nor restorer, Vico's thought judges us from the vantage point of his awareness of the definitive contradictions of social evolutions. This is the reason why, since 1992, I wanted to speak about the Fabbrica della mente of our author, about of a «doubled Reason», and I have no arguments, almost thirty years later, to renounce to this first formulation.

KeYwords: G. Vico, 350 th Anniversary, «unfolded reason», nihilism, decadence, romanity, B. Pinchard.

\section{Vico cieco nel suo centenario}

RIASSUNTO: Né emancipatore né restauratore, il pensiero di Vico ci giudica dall'elevato punto di vista della sua coscienza circa le contraddizioni definitive delle evoluzioni sociali. Questo è il motivo per cui, dal 1992, ho voluto parlare, a proposito della Fabbrica della mente del nostro autore, di una «Ragione raddoppiata», e non ho motivi, a distanza di trent'anni da allora, per rinunciare a questa prima formulazione.

PAROLE CHIAVE: G. Vico, $350^{\circ}$ Anniversario, «Ragione raddoppiata», nichilismo, decadenza, romanità, B. Pinchard.

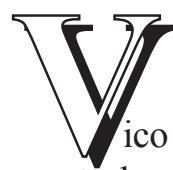

aceptar esta humillación, pues forma parte del estilo de su autoridad. Tal como a Chateaubriand le gustaba repetir a propósito de Pascal: leer las notas a pie de página es como mirar la choza del camellero al pie de las pirámides. Por más que multipli- 
quemos las ediciones cada vez más exactas, más cultas, mejor escritas, nos tropezamos con el mismo obstáculo. Ahora que hemos exprimido suficientemente al Vico padre de la filosofía de la historia, ahora que el Vico sin naturaleza puede dialogar sin consecuencia con el Vico sin metafisica, que el Vico libertino puede cruzarse sin rozar con el Vico tridentino, ¿qué monumento vamos a erigir al filósofo partenopeo? La sirena de Nápoles siempre muere de amor en la playa mirando alejarse a Ulises, pero el orgulloso navegante continúa alejándose del nihilismo sin volver la mirada a la bella moribunda. Por un instante parece que solo el Vesubio alimente un fuego digno de esta famosa "Ciencia nueva" y esperamos la próxima erupción en Pompeya para decidir qué hacer con el legado que el hijo del librero ha dejado tras su biblioteca en llamas. Como Tucídides, Vico ha dejado una adquisición "para siempre", pero nadie sabe descifrar las columnas de Hermes donde yacen los secretos de su grandeza.

Por mucho que la sepultura de Vico haya sido profanada en el fondo de una sacristía por arqueólogos aventureros, la luz de su tumba permanece siempre la misma en el campo de Arcadia: esperando que un Cicerón la descubra, tal como hizo con la de Arquímedes. El orbe que la coronaba cayó al suelo hace tiempo a falta del despertar de una metafísica capaz de mantenerlo en el borde inestable de los altares del mundo. Yace entre los hierbajos y los cipreses atormentados que renacen con la promesa de las ruinas ¿Para qué volver a levantar estas arquitecturas caídas? Solo un eterno retorno prometería alzar de nuevo el edificio antiguo. Vico formuló el oráculo, pero nada ha perturbado el severo pórtico.

Hay quienes podrían sorprenderse de que yo no le divise un futuro "crítico" a la Ciencia nueva. Su designio de ciencia la alienaría entre las empresas gallardas de la Ilustración y el camino hacia Vico se identificaría con un camino hacia el progreso de una humanidad deshaciéndose de las ilusiones de su juventud. Pero, ¿quién no ve que el pensamiento crítico no tiene ningún futuro en el mundo de sumisión que se anuncia? ¿Quién no ve que la crítica pertenece a las fases preparatorias del Gran mercado y que la emancipación prometida, al final, solo ha encontrado una realización comercial? La hora de los mesianismos ha terminado, solo quedan momentos de estupefacción más o menos cómplices. Quienes imploran a la Universidad que prolongue imperturbablemente la denuncia de las ilusiones no hacen sino prolongar su posición de fuera de juego en la comunicación universal. Hacer de Vico el propagandista impenitente de un mundo transparente y libre sería precipitar a Vico hacia un mutismo definitivo. Si Vico tiene este valor de admonición que todo el mundo le reconoce, si del frontón de su templo siempre se desprende una luz de tormenta, es precisamente porque ha mostrado los límites definitivos del pensamiento crítico: primero porque todas las ilusiones terminan por volver según la ley del Eterno retorno, pero sobre todo porque el espíritu crítico es un espíritu "moderno" y porque nunca un espíritu moderno, imbuido de su Sapienza risposta, su teoricismo, podrá tener idea alguna de la vitalidad de las sociedades vivas. Las abstracciones militantes son 
la muerte de la historia y del sociologismo crítico, como todo pensamiento que pretende prolongar la era de la sospecha, no solo son perjudiciales para la ciencia, sino también para la vida social y para la realización de todo proyecto de civilización.

No se puede, por este motivo, colocar a Vico en el campo tradicionalista que quiere preservar las costumbres y las instituciones sin reconocer nunca que estas son permanentemente arrastradas por el movimiento de su disolución. La muerte obsesiona a la sociedad y si esta se revuelve ante ella en nombre de principios "reaccionarios", es que la muerte ya la ha apresado. El mundo social corre a su disolución y es su única vida. Se puede adornar esta verdad confiando a Hércules políticos la tarea de hacer penetrar los auspicios aristocráticos en las muchedumbres en pos de reconocimiento, estos mediadores no hacen sino propagar un incendio que las masas podrían transformar en desastre. La igualdad que se sitúa en el corazón de toda renovación del contrato social no tiene, evidentemente, otro futuro que el que le depara el Capital, a costa de una oleada de la que las migraciones actuales solo dan una somera idea. Marx aquí se muestra mucho más lúcido que los propagadores del socialismo utópico.

$\mathrm{Ni}$ emancipador ni restaurador, el pensamiento de Vico nos juzga desde la atalaya de su conciencia de contradicciones definitivas de las evoluciones sociales. Esta es la razón por la que, desde 1992, he querido hablar, a propósito de la Fabbrica della mente de nuestro autor, de una "Razón desdoblada", y no tengo argumentos, casi treinta años después, para renunciar a esta primera formulación. La cifra 2 le conviene mejor que toda unificación platónica o toda triada resolutoria de contradicciones. La numerología viquiana se repliega alrededor del 2 y es por este motivo que se resiste a todas las simplificaciones. Ella comparte con Blaise Pascal la idea de que la "clave de la cifra" solo se encuentra en la irremediable dualidad del hombre: con la diferencia de que, para Pascal, esta dualidad reside en la repartición entre «el hombre caído» y «el hombre salvado», mientras que en Vico esta se escinde entre el mundo democrático y reflexivo de las sociedades humanizadas y el mundo latente, injusto y primordial de las sociedades fundadas en un derecho divino. La dualidad fundadora está aquí de manera manifiesta entre el paganismo y el cristianismo, esta dualidad que parece superada en Occidente desde que Dante declarara los dioses de Virgilio «falsi e bugiardi», falsos y mentirosos. Pero Vico apareció y ha hecho renacer la vieja obsesión que había desencadenado la voluntad exterminadora de las antiguas divinidades, aquella que se había primeramente apoderado de San Agustín en la Ciudad de Dios. De repente, Roma ya no ha reinado solo como un lugar de tránsito entre la Babilonia terrestre y la Ciudad celeste, sino que Roma ha regresado con Jano destinado a la Summa y a los Initia. La Summa pertenece quizá al Júpiter del día, pero los Initia permanecen secretamente operantes, aunque cada día más latentes. Pero tal como Vico lo ha mostrado: fundar es esconder, $\mathrm{y}$ «condere urbem», fundar Roma, es enterrarla tanto como elevarla. Así, la Ciencia nueva solo era nueva porque mantenía vivo el Sol invictus de Roma. 
Puedo por lo tanto resumir mi lectura de Vico en esta simple fórmula: Vico no es ni "adelantado", ni "arretrato", atrasado; es romano, indefinidamente romano. Vico ni aporta una filosofía de la historia, ni anuncia una filosofía de la decadencia, ni aboga por una ética de campus; contribuye solo a alargar la sombra de Roma en nuestras construcciones arbitrarias, en nuestras legislaciones libertarias, en nuestros universales únicamente reglamentarios. Vico no pertenece a la norma, sino a estas «rivalidades de auspicios» que Vico ha mostrado como bases del fundamento simbólico de toda sociedad. Para él, el único espacio público de intersubjetividad solo puede ser el foro en el que se confrontan las rivalidades no enmascaradas del patricio y del plebeyo, según las leyes contrarias de sus divinidades. Vico no aboga ni por una sociedad abierta, ni por una sociedad pacífica. No hay identidad feliz en la lucidez de la Ciencia nueva. Solo hay un destino guiado por el destello de la Providencia.

Quisiéramos a un Vico sin Providencia, o nada de Vico por miedo a encontrarla. Pero la Providencia de Vico no es más que una visión de totalización del tiempo y si esta Providencia ha encontrado su origen en la Pronoia de Proclo y en el Prólogo del código Justiniano, moviliza un poder substancial único prolongando a Spinoza en el campo social sin, por ello, compartir su política. Se podría incluso decir que la Ciencia nueva es una política spinozista que resiste a las tentaciones de simplificación de la política del mismo autor. Por tanto, la cuestión no es la Providencia o la Filosofía, sino más bien la Providencia con la filosofía, o la renuncia a toda filosofía. La Providencia de Vico converge en una "unidad del Espíritu" $\mathrm{y}$, de esta manera, se hace evidentemente filosófica, no puede compararse a las Providencias teológicas haciendo caso omiso de las complejidades de la historia y de la política. Es suficiente con recordar cómo Agustín mira Roma saqueada bajo Alarico, para entender que Vico está del lado de los grandes conflictos humanos, sin hacer nunca juicios de las faltas predestinadas de los hombres.

Vico filósofo es ciertamente incomprensible, indescifrable, desalentador y contradictorio, ¿pero no es adivinatorio? Quien comprendiera a Vico podría anticipar nuestro destino. Vico es el Occidente, con armas y bagajes, perdido en sus ciclos y en el genio de su memoria, que emigra hacia su futuro, cegado como Orión yendo de aquí para allá y tropezándose, bajo los ojos de la diosa impasible, con todos los árboles del camino. Vico es el Occidente, porque Vico es ciego, porque ningún Celadón está subido a sus hombros, porque no deja de buscar el sol al amanecer. Vico es ciego y es el último sacramento de su grandeza: porque es nuestro Homero y porque no se canta la Ilíada y la Odisea sin ser ciego, es decir, poeta, ante los acontecimientos ya consumidos del tiempo presente.

\section{১oর [Traducción del francés por Fernanda Pérez Alors]}

Últimas PUblicaciones Del Autor: Marx à rebours, Kimé, París, 2015; y Hespérie, contribución "virgiliana" a una política occidental: más allá de Heidegger y de las guerras de religión, Kimé, París, 2018. 